\title{
Investigating the Molecular Origins of Responsiveness in Functional Silicone Elastomer Networks
}

\author{
Julie A. Crowe-Willoughby, ${ }^{\dagger}, \S$ Derrick R. Stevens, ${ }^{\star}$ Jan Genzer $^{*},{ }^{\dagger}$ and Laura I. Clarke ${ }^{*}$, \\ ${ }^{\dagger}$ Department of Chemical \& Biomolecular Engineering, NC State University, Raleigh, \\ North Carolina 27695-7905, and Department of Physics, NC State University, Raleigh, \\ North Carolina 27695-8202. ${ }^{\S}$ Present address: MeadWestvaco, Center for Packaging Innovation, \\ 1021 Main Campus Drive, Raleigh, North Carolina 27606
}

Received February 28, 2010; Revised Manuscript Received April 25, 2010

\begin{abstract}
Dielectric, calorimetric, and dynamic mechanical measurements were performed to delineate the types and dynamic rates of molecular scale motion in modified poly(vinylmethyl siloxane) (PVMS) stimuli-responsive networks, where pendent groups of the form $-\mathrm{S}-\left(\mathrm{CH}_{2}\right)_{n}-\mathrm{OH}$ were chemically attached to the vinyl moiety of PVMS. The glass transition temperature $\left(T_{\mathrm{g}}\right)$ for the unsubstituted PVMS network matches that previously reported for linear PVMS indicating that the flexibility of the polymer chains is unaffected by the network cross-linking. In contrast, $T_{\mathrm{g}}$ increases with the introduction of pendent groups of the type $-\mathrm{S}-\left(\mathrm{CH}_{2}\right)_{n}-\mathrm{CH}_{3}$ or $-\mathrm{S}-\left(\mathrm{CH}_{2}\right)_{n}-\mathrm{OH}$, where $n$ is 2,6 , or 11 , as the different groups constrain the siloxane backbone to differing degrees. The macroscopic response time and amplitude, as previously measured by dynamic contact angle, are correlated with the observed glass transition temperatures. One conclusion is that the flexibility of the network and the interactions between pendent groups affect responsiveness.
\end{abstract}

\section{Introduction}

Responsive materials alter their physical or chemical properties spontaneously when exposed to an external stimulus (e.g., an electromagnetic field, mechanical strain, temperature variation, exposure to a fluid, or change of $\mathrm{pH}$ or ionic strength). ${ }^{1-4}$ While the response is primarily due to structural alterations occurring at the microscopic level, i.e., changes in molecular conformation, these microscopic adjustments result in variations in measurable macroscopic characteristics, such as material shape, size, color, or wetting properties. When considering applications of these stimuli-responsive materials, three quantities are important: (1) the magnitude of the response, (2) the speed of the response, and (3) any hysteresis associated with the switching, such as a long reset time after stimulation. Speed of response should be tunable for specific applications. For instance, an ideal material for sensing possesses a large, fast response with little hysteresis. However, all three of these parameters can be interlinked; e.g., alterations to increase the response magnitude could also unintentionally increase response time.

In this work, we explore the relationship between structural parameters, microscopic dynamics, and macroscopic response time for silicone elastomer networks acting as stimuli-responsive surfaces. We employ differential scanning calorimetry (DSC), dynamic mechanical thermal analysis (DMTA), and dielectric relaxation spectroscopy (DRS) to examine thoroughly various molecular motions in responsive surfaces made from modified poly(vinylmethyl siloxane) (PVMS) networks. We then correlate these molecular motions to the measured macroscopic response (as determined by dynamic contact angle (DCA)) as a function of material structure.

In the PVMS network system, the cross-links of the network provide a solid-like nature, despite the low $T_{\mathrm{g}}$ of linear PVMS

\footnotetext{
*Corresponding authors: (L.I.C.) laura_clarke@ncsu.edu; (J.G.) jan_genzer@ncsu.edu.

$(\approx 150 \mathrm{~K})$ which allows for a high degree of flexibility at room temperature. ${ }^{5,6}$ Due to the difference in surface energies between the vinyl and methyl groups, PVMS is moderately amphiphilic. Because the network is flexible, the side-chains can rearrange readily when placed in contact with another medium, thus delivering the component resulting in the lowest interfacial energy (dependent on the surroundings) to the interface. For instance, the hydrophobic methyl groups are exposed to the surface when the material is placed in air. When in contact with a hydrophilic environment, i.e., water, the more hydrophilic vinyl groups migrate to the surface (Figure 1). As the energy difference between the vinyl and methyl moieties is small, we have grafted mercaptoalkanols at the vinyl group via the thiol-ene reaction thereby increasing the contrast between the opposing termini and enhancing the switching property. ${ }^{5,6} \mathrm{We}$ previously studied the kinetics of surface rearrangement of the substituted networks (with pendent $-\mathrm{S}-\left(\mathrm{CH}_{2}\right)_{n}-\mathrm{OH}$ groups) by monitoring wettability changes using both static and dynamic contact angle measurements. In particular, we established that both the rate and magnitude of switching decreased with increasing length of the methylene spacer (n) separating the $-\mathrm{OH}$ terminus from the siloxane network. ${ }^{5,6}$

The aim of this work is to observe and characterize the molecular-level dynamics in PVMS-based networks and to determine how these molecular motions are altered by (1) the length of the methylene spacer in the mercaptoalkanol pendent group and (2) the end-terminus of the pendent group (-OH vs $\left.-\mathrm{CH}_{3}\right)$. We perform new analysis of data on the macroscopic network response and discuss how the dynamics at a molecular level influence the macroscopic properties. In general, the response time of a stimuli-responsive material will depend not only on the magnitude of the interfacial driving force (i.e., the difference in interfacial energy between the two switching states) but also on the innate dynamics within the material. In particular, in the substituted PVMS networks, the pendent groups must move through the network in order to emerge at the surface; thus the 

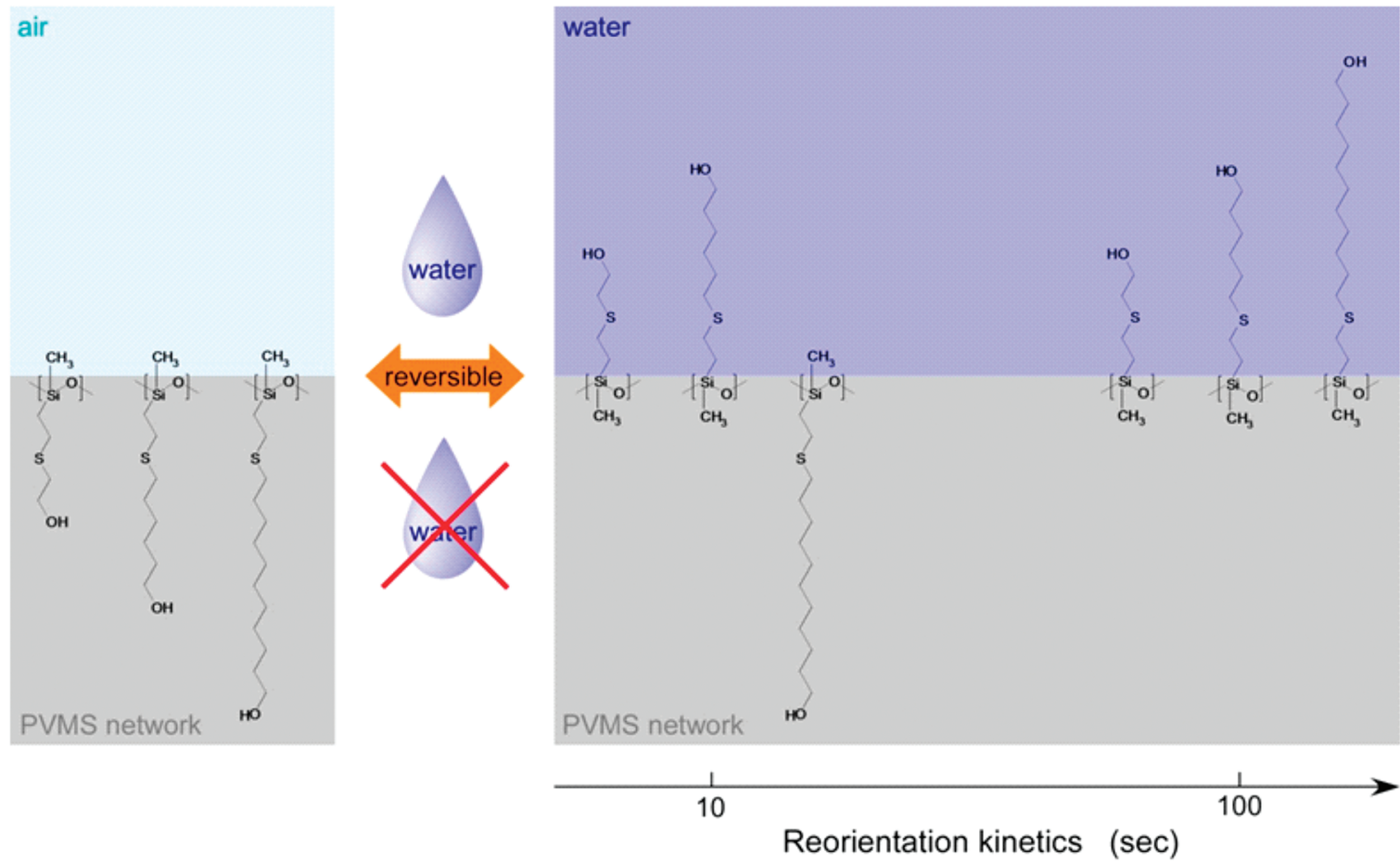

Figure 1. Schematics depicting the reorientation kinetics of PVMS $-\mathrm{S}-\left(\mathrm{CH}_{2}\right)_{n}-\mathrm{OH}$ samples $(n=2,6$, and 11$)$ between hydrophobic (left) and hydrophilic (right) states.

Table 1. Properties of Bare and Modified Silicone Elastomer Networks Assessed with Differential Scanning Calorimetry (DCS), Dynamical Mechanical Thermal Analysis (DMTA), and Dielectric Relaxation Spectroscopy (DRS)

\begin{tabular}{|c|c|c|c|c|c|c|c|c|}
\hline \multirow[b]{2}{*}{ material } & \multicolumn{3}{|c|}{$T_{\mathrm{g}}(\mathrm{K})^{a}$} & \multicolumn{3}{|c|}{$T_{\mathrm{m}}(\mathrm{K})^{b}$} & \multicolumn{2}{|c|}{ Local mode $(\mathrm{K})$} \\
\hline & $\mathrm{DSC}$ & $\mathrm{DMTA}^{c}$ & $\mathrm{DRS}^{d}$ & DSC & DMTA $^{c}$ & $\mathrm{DRS}^{e}$ & $\mathrm{DMTA}^{c}$ & $\mathrm{DRS}^{f}$ \\
\hline PDMS & & $156 \pm 5$ & $146-166$ & 230 & 224 & $245-250$ & & \\
\hline PVMS & & $149 \pm 3$ & $140 \pm 5$ & & & & & \\
\hline $\mathrm{PVMS}-\mathrm{S}-\left(\mathrm{CH}_{2}\right)_{2}-\mathrm{OH}$ & 215 & $236 \pm 3$ & $230 \pm 10$ & $\mathrm{~N} / \mathrm{A}$ & $\mathrm{N} / \mathrm{A}$ & N/A & $189 \pm 2$ & $181 \pm 3$ \\
\hline $\mathrm{PVMS}-\mathrm{S}-\left(\mathrm{CH}_{2}\right)_{6}-\mathrm{OH}$ & 208 & $228 \pm 12$ & $210 \pm 20$ & $\mathrm{~N} / \mathrm{A}$ & $\mathrm{N} / \mathrm{A}$ & N/A & $188 \pm 2$ & $180 \pm 10$ \\
\hline PVMS-S- $\left(\mathrm{CH}_{2}\right)_{11}-\mathrm{OH}$ & 284.5 & $240 \pm 40$ & $270-290^{g}$ & $306 \pm 7$ & $303 \pm 9$ & $300-320$ & $189 \pm 8$ & $201 \pm 5$ \\
\hline PVMS-S- $-\left(\mathrm{CH}_{2}\right)_{2}-\mathrm{CH}_{3}$ & & $190 \pm 2$ & & & & & $162 \pm 2$ & \\
\hline PVMS-S- $-\left(\mathrm{CH}_{2}\right)_{11}-\mathrm{CH}_{3}$ & 210 & & $265 \pm 5$ & & & $290-300$ & (n) & $140 \pm 5$ \\
\hline
\end{tabular}

dynamics of the larger system (e.g., the segmental dynamics related to the $T_{\mathrm{g}}$ of the substituted network) may affect responsiveness. Beyond the structure-response correlations pertaining to this specific system, these observations are also beneficial for developing rational design strategies for the larger class of stimulus-response surfaces consisting of polymer chains anchored to an underlying substrate. ${ }^{2}$

We will examine six polymer networks whose molecular parameters are summarized in Table 1. Those include: PVMS, PVMS-S- $\left(\mathrm{CH}_{2}\right)_{2}-\mathrm{OH}, \mathrm{PVMS}-\mathrm{S}-\left(\mathrm{CH}_{2}\right)_{2}-\mathrm{CH}_{3}, \mathrm{PVMS}-\mathrm{S}-$ $\left(\mathrm{CH}_{2}\right)_{6}-\mathrm{OH}, \mathrm{PVMS}-\mathrm{S}-\left(\mathrm{CH}_{2}\right)_{11}-\mathrm{OH}$, and PVMS $-\mathrm{S}-\left(\mathrm{CH}_{2}\right)_{11}-$ $\mathrm{CH}_{3}$. Data from poly(dimethylsiloxane) (PDMS) networks are shown for comparison. The PVMS-S- $\left(\mathrm{CH}_{2}\right)_{n}-\mathrm{CH}_{3}$ species represent a special case of amphiphiles whose wettability decreases with increasing alkyl chain length. In this work, $-\mathrm{CH}_{3}$ terminated networks will serve as a control to understand the differences in side-chain interactions due to the terminal $-\mathrm{OH}$ group.

\section{Experimental Methods}

Substrate preparation of modified PVMS networks and the experimental details of the static and dynamic contact angles have been previously reported. ${ }^{5,6}$ Elastomeric PVMS network substrates were synthesized by following an alkoxy-cure method of PVMS $\left(M_{\mathrm{n}} \approx 40 \mathrm{kDa}\right)$ through end-group cross-linking as described elsewhere. ${ }^{7}$ The storage modulus of the PVMS networks was measured to be $\approx 8 \times 10^{4} \mathrm{~Pa}$ after Soxhlet extraction using toluene for at least $48 \mathrm{~h}$ followed by drying at $75^{\circ} \mathrm{C}$ under $30 \mathrm{mmHg}$ vacuum. The vinyl moieties on PVMS were subsequently saturated via azobis(isobutyronitrile)- (AIBN)- initiated thiol-ene radical addition of $\mathrm{HS}-\left(\mathrm{CH}_{2}\right)_{n}-\mathrm{OH}(n=2,6$, and 11). ${ }^{8}$ After the reaction, the PVMS $-\mathrm{S}-\left(\mathrm{CH}_{2}\right)_{n}-\mathrm{OH}$ samples were re-extracted, dried, and stored in a low-humidity chamber. Experiments using infrared spectroscopy in the attenuated reflection mode confirmed that the grafting density of $\mathrm{S}-\left(\mathrm{CH}_{2}\right)_{n}-\mathrm{OH}$ was approximately equal in each sample.

Dynamic Mechanical Thermal Analysis (DMTA). DMTA was performed using a TA Instrument Q800 operating with single cantilever geometry. The dried polymers films were cut into approximately $25 \times 10 \times 1.5 \mathrm{~mm}^{3}$ rectangles. Storage modulus $\left(E^{\prime}\right)$, loss modulus $\left(E^{\prime \prime}\right)$, and loss tangent $(\tan \delta)$ were recorded at a heating rate of $3{ }^{\circ} \mathrm{C} / \mathrm{min}$ from -150 to $+130{ }^{\circ} \mathrm{C}$ and at a test frequency of $1 \mathrm{~Hz}$. The amplitude was set to be within the linear viscoelastic regime.

Differential Scanning Calorimetry (DSC). DSC was performed using a TA Instrument Q100. Two runs were carried out for each sample in the range of -80 to $+130{ }^{\circ} \mathrm{C}$ with a heating rate of $3^{\circ} \mathrm{C} / \mathrm{min}$ under a nitrogen atmosphere. The glass 
transition $\left(T_{\mathrm{g}}\right)$ values were determined as the onset points from the second scans if applicable. The melting point $\left(T_{\mathrm{m}}\right)$ was taken as the maximum of the endothermic peak.

Dynamic Relaxation Spectroscopy (DRS). DRS utilized a highly sensitive Andeen-Hagerling capacitance bridge operating at $50 \mathrm{~Hz}-20 \mathrm{kHz}$. Samples were mounted onto planar interdigitated electrodes, which enabled dielectric measurements on small amounts of material. This technique has been utilized previously for dielectric measurements on self-assembled monolayers ${ }^{9}$ and polymers. ${ }^{10}$ We specifically chose the narrow-band, highly sensitive technique, rather than conventional broad-band dielectric spectroscopy, so that we could measure small volumes of material from the same samples used for wettability measurements.

DRS Analysis. Dielectric relaxation spectroscopy utilizes the sample as a dielectric within a capacitor and measures the complex dielectric constant $\left(\varepsilon^{*}=\varepsilon^{\prime}-i \varepsilon^{\prime \prime}\right)$ under application of an AC electric field ${ }^{11}$ at frequency $\omega$. The output of the precision bridge used in these experiments is capacitance $(C)$ and tan $\delta$ measured as a function of frequency and temperature. $C=\mathrm{A} \varepsilon^{\prime}$, where $\mathrm{A}$ is a geometrical factor related to the size and shape of the capacitor, whereas $\tan \delta=\varepsilon^{\prime \prime} / \varepsilon^{\prime}$. Ionic backgrounds were modeled as $\tan \delta=(A / T) \exp \left(-E_{i} / k T\right) / \omega^{\mathrm{s}}$, where $A$ is a constant related to the DC conductivity, the exponential term reflects the temperature dependence of ionic carriers with a characteristic barrier $E_{i}$, and $s$ is dependent on the nature of ionic diffusion and can vary from 0 to $1.2,13$

The step in the capacitance or the more easily observed peak in $\tan \delta$ at $1 / \tau=\omega$ allows for determination of $\tau$ (the characteristic relaxation time or average time between reorientation events) as a function of temperature for a particular applied field frequency $\omega .{ }^{11,12}$ This temperature dependence can then be fitted to the Arrhenius form, $1 / \tau=\omega_{\mathrm{o}} \exp (-\Delta U / k T)$ to determine $\omega_{\mathrm{o}}$, the attempt or libration frequency and $\Delta \mathrm{U}$ the barrier to reorientation. For independent or noninteracting relaxations, where the Arrhenius form is appropriate, this analysis yields physically interpretable values (e.g., $\omega_{0} \approx 10^{13}-10^{15} \mathrm{rad} / \mathrm{s}$ ); however, for interacting objects where the barrier $(\Delta U)$ changes with temperature, particularly for glassy relaxations, fitting with the Arrhenius form produces artificially high apparent values for $\omega_{\mathrm{o}}$ and $\Delta \mathrm{U}$. In this case, a more appropriate analysis utilizes the empirical Vogel-Fulcher-Tammann (VFT) form, ${ }^{14-16} 1 / \tau=$ $\omega_{o} \exp \left[-B /\left(T-T_{\mathrm{o}}\right)\right]$, where the argument of the exponent provides a barrier that increases with decreasing temperature $(\mathrm{B}$ is a constant.). $T_{\mathrm{o}}$ is a temperature below which all motion has ceased and in our fits, $\omega_{\mathrm{o}}$ is held at $10^{14} \mathrm{rad} / \mathrm{s}$ to reduce the number of free parameters. Glassy relaxations are quantified by defining $T_{\mathrm{g}}$ as the temperature at which $\tau=100 \mathrm{~s},{ }^{17}$ determined by fitting the measured $\tau$ versus T with the VFT form and extrapolating to large $\tau$.

In this work, we plotted $\ln (1 / \tau)$ versus $1 / T$ and fit with either the Arrhenius or VFT forms as appropriate to determine either $\Delta \mathrm{U}$, the barrier to rotation, or $T_{\mathrm{g}}$ for glassy relaxations. Ionic backgrounds were removed from the data for PVMS-S$\left(\mathrm{CH}_{2}\right)_{2}-\mathrm{CH}_{3}$ and PVMS $-\mathrm{S}-\left(\mathrm{CH}_{2}\right)_{6}-\mathrm{OH}$ samples. For relaxations within interacting side-chains, which are not a glassy system per se, but which display an elevated apparent $\omega_{\mathrm{o}}$ value, we utilized a Starkweather analysis. Starkweather argued that there are significant entropy changes in cooperative relaxations, in contrast with $\Delta S=0$ for a simple independent motion, and that this value could be used to quantify the level of interaction in different systems. ${ }^{18}$ In this analysis, the Arrhenius form is used to fit the data and the observed activation energy $\Delta U$ and peak position $\mathrm{T}^{\prime}$ are transformed into a $\Delta S$ value as: $\Delta S=\Delta U-$ $k\left[1+\ln (k / 2 \pi h)+\ln \left(T^{\prime} / f\right)\right]$, where $T^{\prime}$ is the temperature at which the relaxation is $f \mathrm{~Hz}$. In our case, we utilized $\Delta U$ values from Arrhenius fits, and performed the Starkweather analysis at $1 \mathrm{kHz}$, in the middle of our experimental frequency range.

\section{Results}

A. Macroscopic Response. The macroscopic response of the substituted PVMS networks was characterized previously

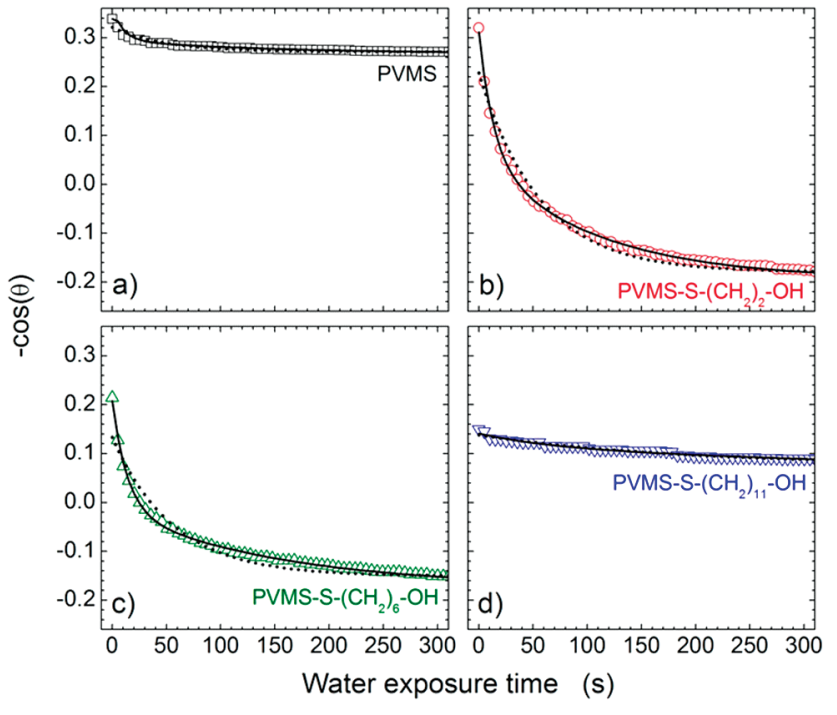

Figure 2. Time dependence of the negative cosine of the contact angle $(\theta)$ measured by DCA (second cycle) for (a) PVMS (black squares), (b) PVMS-S- $\left(\mathrm{CH}_{2}\right)_{2}-\mathrm{OH}$ (red circles), (c) PVMS $-\mathrm{S}-\left(\mathrm{CH}_{2}\right)_{6}-\mathrm{OH}$ (green up-triangles), and (d) PVMS-S- $\left(\mathrm{CH}_{2}\right)_{11}-\mathrm{OH}$ (blue downtriangles). The dotted and solid lines represent the best fit to eqs 1 and 2 , respectively, as described in the text.

by studying the cycling between hydrophobic (dry) and hydrophilic states (wet) states by dynamic contact angle (DCA). The degree of wettability change and the rate of response, i.e., the variation of the water contact angle $(\theta)$ with time $(\tau)$, were shown qualitatively to decrease with increasing the number of methylene units $(n)$ in the mercaptoalkanol hydrocarbon spacer. Moreover, long linkers were seen to cocrystallize locally thus freezing the conformation until it was relieved by heating the sample above the melting point of the alkane crystallites. 5,6 The open symbols in Figure 2 depict representative examples of such wettability changes recorded for PVMS (squares), PVMS-S- $\left(\mathrm{CH}_{2}\right)_{2}-$ $\mathrm{OH}$ (circles), $\mathrm{PVMS}-\mathrm{S}-\left(\mathrm{CH}_{2}\right)_{6}-\mathrm{OH}$ (up-triangles), and PVMS-S- $\left(\mathrm{CH}_{2}\right)_{11}-\mathrm{OH}$ (down-triangles). These data reveal that while PVMS exhibits a relatively modest, but fast, wettability change, PVMS-S- $\left(\mathrm{CH}_{2}\right)_{2}-\mathrm{OH}$ and PVMS$\mathrm{S}-\left(\mathrm{CH}_{2}\right)_{6}-\mathrm{OH}$ display similar reorganization kinetics, along with a larger change in wetting, upon transitioning from a hydrophobic to a hydrophilic environment. PVMS$\mathrm{S}-\left(\mathrm{CH}_{2}\right)_{11}-\mathrm{OH}$ does not exhibit this large change in wettability during the cycling behavior even before the sidechains crystallize.

We extend these observations by quantitatively interpreting the DCA data. We first analyzed the DCA data by fitting each cycle individually to the first order exponential decay:

$$
-\cos (\theta)=A+B_{1} \exp \left(-\beta_{1} t\right)
$$

In eq $1, A, B_{1}$, and $\beta_{1}$ were used as fitting parameters; $\beta_{1}$ represents an inverse of a characteristic relaxation time. We averaged the fitting exponents from runs 2-10 (excluding run number 1 because of unknown sample history during preparation) for PVMS, PVMS $-\mathrm{S}-\left(\mathrm{CH}_{2}\right)_{2}-\mathrm{OH}$, and PVMS $-\mathrm{S}-\left(\mathrm{CH}_{2}\right)_{6}-\mathrm{OH}$, and cycles $2-4$ for PVMS $-\mathrm{S}-$ $\left(\mathrm{CH}_{2}\right)_{11}-\mathrm{OH}$ (after the fourth cycle the structure froze because of local cocrystallization among $\left.-\left(\mathrm{CH}_{2}\right)_{11}-\mathrm{OH}\right)$. The dotted lines in Figure 2 denote the values of $-\cos (\theta)$ as a function of time obtained by the best fits to eq 1 . While the fits to PVMS and PVMS $-\mathrm{S}-\left(\mathrm{CH}_{2}\right)_{11}-\mathrm{OH}$ were satisfactory $\left(R^{2}>0.98\right)$, the first order exponential decays did not capture accurately the trends observed in the PVMS $-\mathrm{S}-\left(\mathrm{CH}_{2}\right)_{2}-\mathrm{OH}$ 
and PVMS $-\mathrm{S}-\left(\mathrm{CH}_{2}\right)_{6}-\mathrm{OH}$ specimens. We then reanalyzed the DCA data by fitting to the second order exponential decay:

$$
-\cos (\theta)=A+B_{1} \exp \left(-\beta_{1} \tau\right)+B_{2} \exp \left(-\beta_{2} \tau\right)
$$

The solid lines in Figure 2 represent the best fits to eq 2 with $A, B_{1}, \beta_{1}, B_{2}$, and $\beta_{2}$ being used as fitting parameters. The quality of the fits improved considerably for all data sets. In Figure 3 we plot the values of the decay coefficients $\beta_{1}$ (closed symbols) and $\beta_{2}$ (open symbols) for all substrates. From the data in Figure 3, it is apparent that $\beta_{1}$ decreases systematically with increasing $\mathrm{n}$, while $\beta_{2}$ remains relatively constant for all specimens. Recalling that $\beta_{\mathrm{j}}$ is inversely related to

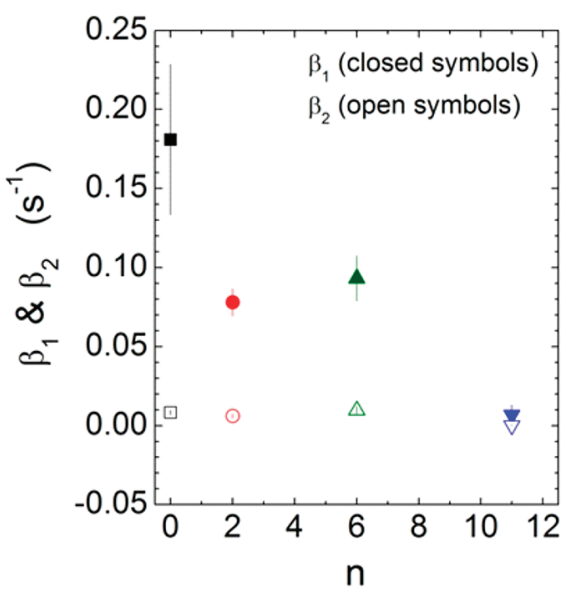

Figure 3. Coefficients in the 2 nd order exponential decay function $\left(\beta_{1}\right.$ : solid symbols, $\beta_{2}$ : open symbols) for PVMS (black squares), PVMS-S- $\left(\mathrm{CH}_{2}\right)_{2}-\mathrm{OH}$ (red circles), PVMS-S- $\left(\mathrm{CH}_{2}\right)_{6}-\mathrm{OH}$ (green up-triangles), and PVMS $-\mathrm{S}-\left(\mathrm{CH}_{2}\right)_{11}-\mathrm{OH}$ (blue down-triangles) as a function of the number of methylene units in PVMS-S- $\left(\mathrm{CH}_{2}\right)_{n}-\mathrm{OH}$. a relaxation time and assuming that the second order exponential decay is a physically reasonable functional form, there are two superimposed processes that govern wettability changes in the specimens: a fast one (given by $\beta_{1}$ ) and a slower one (given by $\beta_{2}$ ). We will return to the issue of second order exponential decay later in the Discussion.

B. . Characterization of Molecular-Level Motion. DSC scans for PVMS, PVMS-S- $\left(\mathrm{CH}_{2}\right)_{2}-\mathrm{OH}$, PVMS $-\mathrm{S}-$ $\left(\mathrm{CH}_{2}\right)_{6}-\mathrm{OH}$, and $\mathrm{PVMS}-\mathrm{S}-\left(\mathrm{CH}_{2}\right)_{11}-\mathrm{OH}$ are shown in Figure 4; the results are also summarized in Table 1. The first three compounds exhibit a clear step-change in the heat

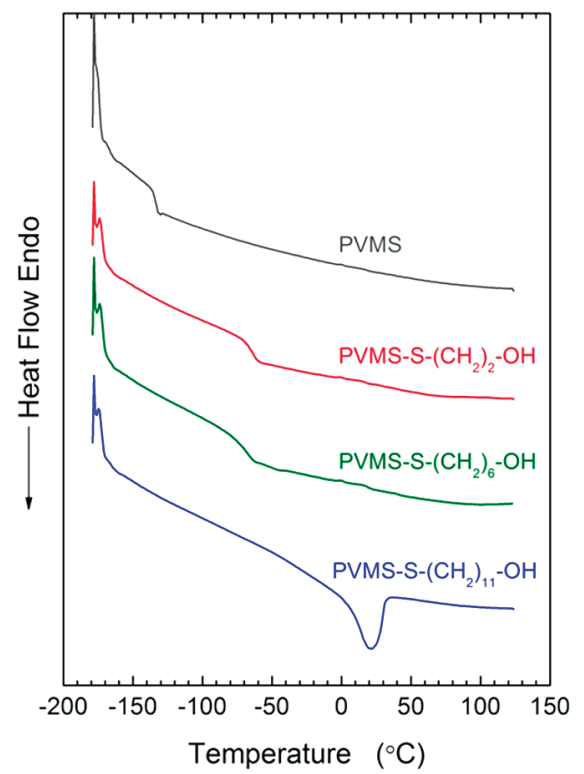

Figure 4. DSC measurements for PVMS and PVMS-modified substrates. The heating rate was $3{ }^{\circ} \mathrm{C} / \mathrm{min}$, see text for details.

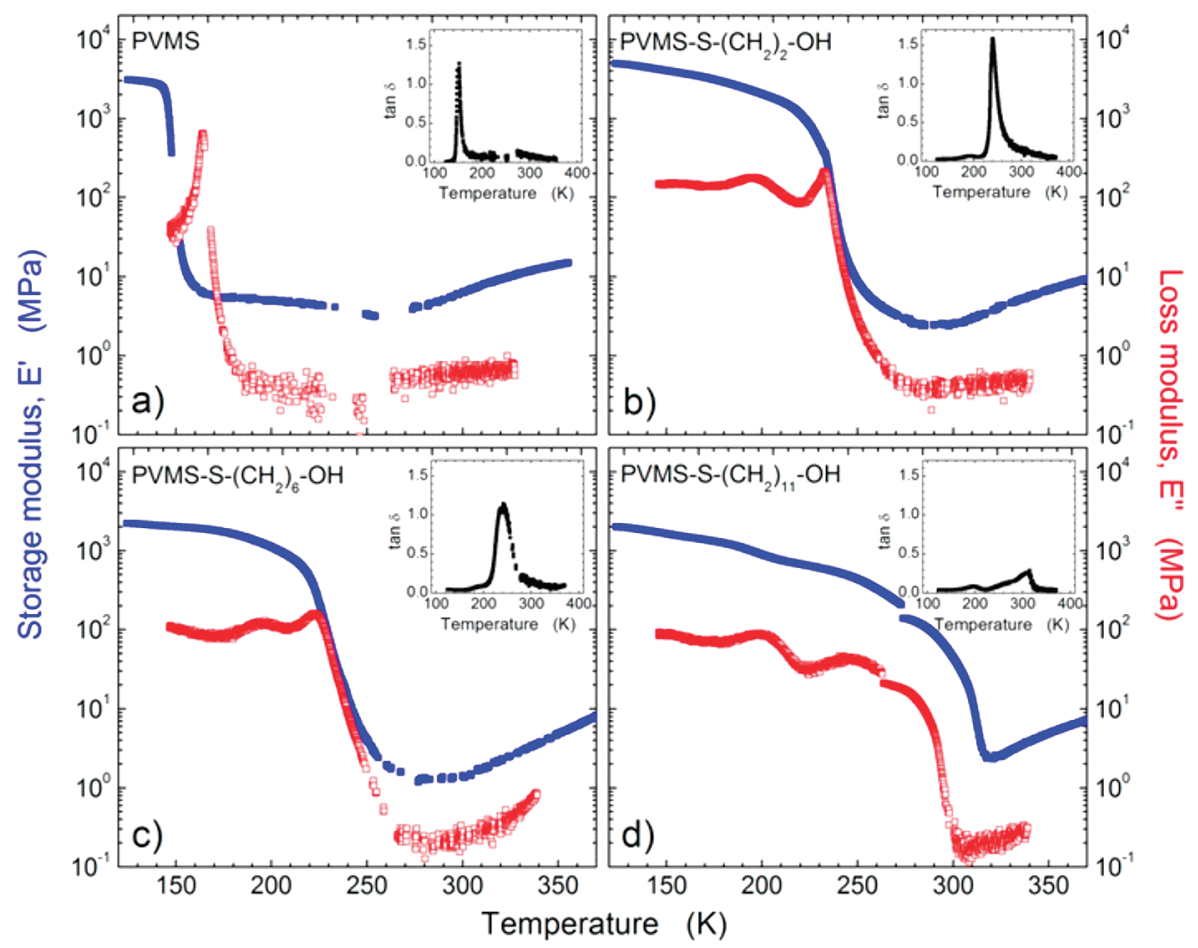

Figure 5. DMTA data for PVMS and PVMS-mercaptanol modified substrates depicting the storage (left ordinate, closed blue symbols) and loss (right ordinate, open red symbols) moduli, $\mathrm{E}^{\prime}$ and $\mathrm{E}^{\prime \prime}$, respectively, for PVMS (a), PVMS $-\mathrm{S}-\left(\mathrm{CH}_{2}\right)_{2}-\mathrm{OH}(\mathrm{b}), \mathrm{PVMS}-\mathrm{S}-(\mathrm{CH})_{6}-\mathrm{OH}(\mathrm{c})$, and PVMS-S- $\left(\mathrm{CH}_{2}\right)_{11}-\mathrm{OH}(\mathrm{d})$. Temperature ramps were performed at a heating rate of $3{ }^{\circ} \mathrm{C} / \mathrm{min}$ and at $1 \mathrm{~Hz}$. Amplitude was set within the linear viscoelastic regime. The inset graphs depict $\tan \delta$, i.e, $\tan \left(E^{\prime} / E^{\prime \prime}\right)$. 


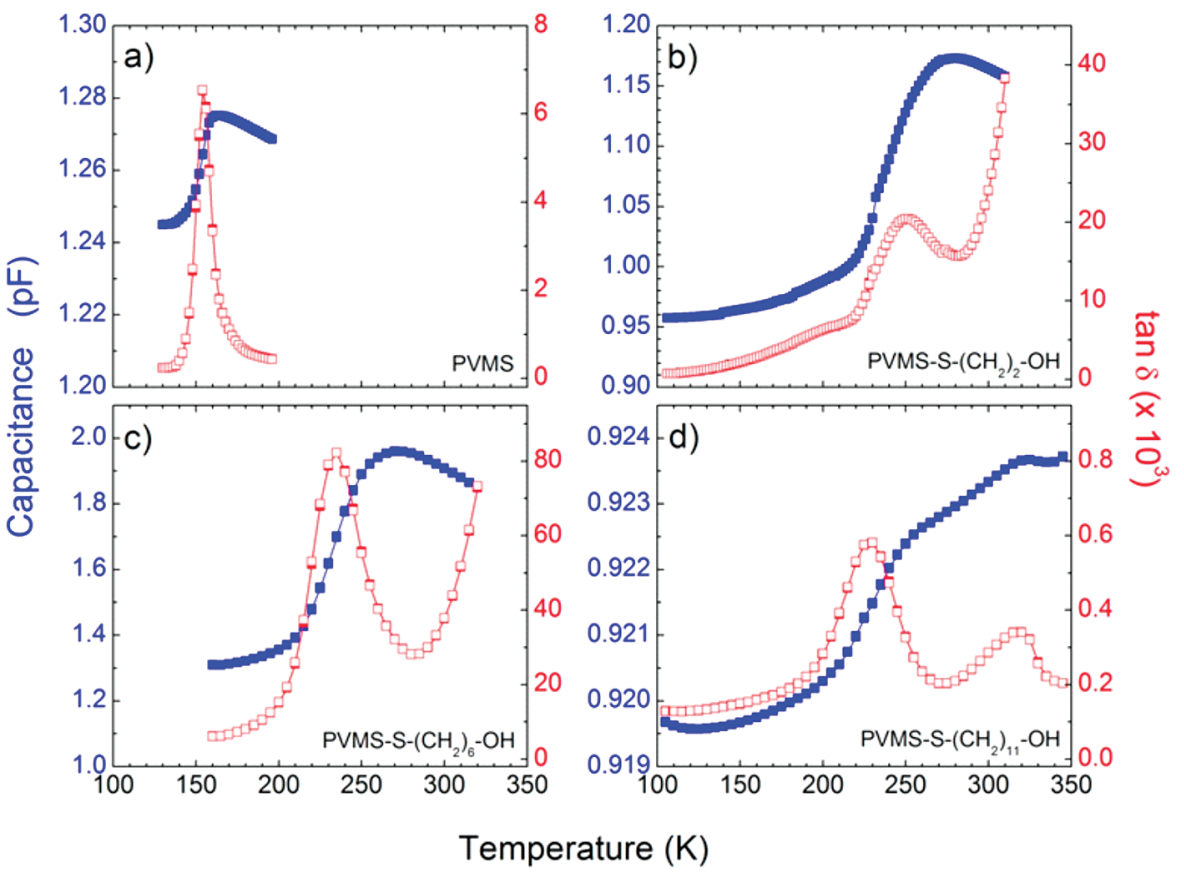

Figure 6. Capacitance (left ordinate, blue solid symbols) and tan $\delta$ (right ordinate, red open symbols) from DRS measurements at $10 \mathrm{kHz}$ for PVMS (a), PVMS-S- $\left(\mathrm{CH}_{2}\right)_{2}-\mathrm{OH}$ (b), PVMS-S $-\left(\mathrm{CH}_{2}\right)_{6}-\mathrm{OH}$ (c), and PVMS-S $-\left(\mathrm{CH}_{2}\right)_{11}-\mathrm{OH}$ (d).

flow output at the glassy transition state plateau. The resultant $T_{\mathrm{g}}$ values are given in Table 1. Data from PVMS$\mathrm{S}-\left(\mathrm{CH}_{2}\right)_{11}-\mathrm{OH}$ reveal a melting transition that results in a distinct endothermic peak superimposed near the glass transition feature. We have previously reported on crystallization of PVMS $-\mathrm{S}-\left(\mathrm{CH}_{2}\right)_{11}-\mathrm{OH}{ }^{5,6}$

DMTA data for PVMS, PVMS-S- $\left(\mathrm{CH}_{2}\right)_{2}-\mathrm{OH}, \mathrm{PVMS}-$ $\mathrm{S}-\left(\mathrm{CH}_{2}\right)_{6}-\mathrm{OH}$, and PVMS $-\mathrm{S}-\left(\mathrm{CH}_{2}\right)_{11}-\mathrm{OH}$ are shown in Figure 5. The largest step change in elastic modulus $\mathrm{E}^{\prime}$, maxima in loss modulus $\mathrm{E}^{\prime \prime}$, and maxima in $\tan \delta\left(E^{\prime} \cong\right.$ $3 G^{\prime}, E^{\prime \prime} \cong 3 G^{\prime \prime}$, and $\left.\tan \delta=E^{\prime \prime} / E^{\prime}\right)$ indicates the position of the $\alpha$ transition $\left(T_{\alpha}\right)$, which is assigned as the glass transition temperature $\left(T_{\mathrm{g}}\right) \cdot{ }^{19,20}$ PVMS exhibits a clear transition at $\approx 150 \mathrm{~K}$ associated with the $T_{\mathrm{g}}$. In PVMS $-\mathrm{S}-\left(\mathrm{CH}_{2}\right)_{2}-\mathrm{OH}$ and $\mathrm{PVMS}-\mathrm{S}-\left(\mathrm{CH}_{2}\right)_{6}-\mathrm{OH}$, the most dramatic change corresponds to the $T_{\mathrm{g}}$; these values match well with those from DSC (cf. Table 1). In addition, a smaller secondary relaxation appearing at a temperature below $T_{\mathrm{g}}$ is present. The locations of these features (labeled as $\beta$ ) are also summarized in Table 1 . The presence of crystallinity complicates the spectrum of PVMS $-\mathrm{S}-\left(\mathrm{CH}_{2}\right)_{11}-\mathrm{OH}$. In this case, the highest temperature feature is due to melting. In addition, there is a feature associated with the glass transition as well as a secondary $(\beta)$ relaxation below $T_{\mathrm{g}}$. In addition to single frequency data, DMTA measurements were taken at a range of frequencies for the PVMS and PVMS $-\mathrm{S}-\left(\mathrm{CH}_{2}\right)_{11}-\mathrm{OH}$ samples. The $\alpha$ and $\beta$ relaxations in PVMS-S $-\left(\mathrm{CH}_{2}\right)_{2}-\mathrm{CH}_{3}$ were also studied by DMTA (cf. Table 1).

DRS spectra at $10 \mathrm{kHz}$ for PVMS, PVMS $-\mathrm{S}-\left(\mathrm{CH}_{2}\right)_{2}-$ $\mathrm{OH}, \mathrm{PVMS}-\mathrm{S}-\left(\mathrm{CH}_{2}\right)_{6}-\mathrm{OH}$, and $\mathrm{PVMS}-\mathrm{S}-\left(\mathrm{CH}_{2}\right)_{11}-\mathrm{OH}$ are plotted in Figure 6 . The trends in the DRS data follow those in the DMTA results. For PVMS a single relaxation is observed which corresponds to the $\alpha$ relaxation in DMTA; whereas both $\alpha$ and sub- $T_{\mathrm{g}}(\beta)$ relaxations are observed in the PVMS $-\mathrm{S}-\left(\mathrm{CH}_{2}\right)_{n}-\mathrm{OH}$ samples. At the frequency utilized for the data depicted in Figure 6, the $\beta$ and $\alpha$ relaxations are merged; however, they can be seen more clearly in Figure 7 , which displays $\tan \delta$ for PVMS $-\mathrm{S}-\left(\mathrm{CH}_{2}\right)_{2}-\mathrm{OH}$ at frequencies

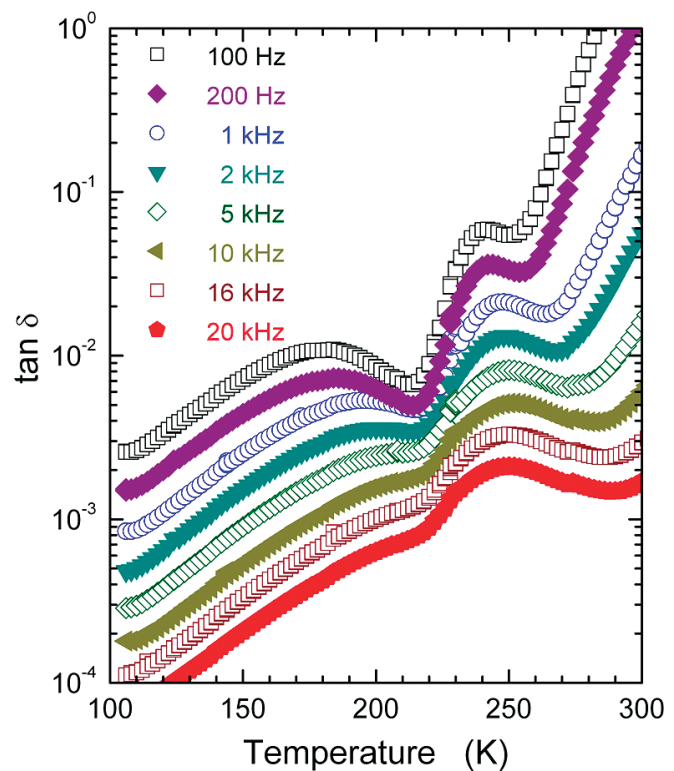

Figure 7. Dissipation factor $(\tan \delta)$ as a function of temperature for PVMS-S $-\left(\mathrm{CH}_{2}\right)_{2}-\mathrm{OH}$. The logarithmic scale enables tracking of the low temperature relaxation. An arbitrary $y$-axis offset was applied to each data set.

varying from $100 \mathrm{~Hz}$ to $20 \mathrm{kHz}$. Figure 8 summarizes the sub$T_{\mathrm{g}}(\beta)$ relaxations for $\mathrm{PVMS}-\mathrm{S}-\left(\mathrm{CH}_{2}\right)_{2}-\mathrm{OH}$, PVMS$\mathrm{S}-\left(\mathrm{CH}_{2}\right)_{6}-\mathrm{OH}$, and PVMS $-\mathrm{S}-\left(\mathrm{CH}_{2}\right)_{11}-\mathrm{OH}$, and PVMS$\mathrm{S}-\left(\mathrm{CH}_{2}\right)_{11}-\mathrm{CH}_{3}$. The $\alpha$ peak for PVMS $-\mathrm{S}-\left(\mathrm{CH}_{2}\right)_{2}-\mathrm{OH}$ and PVMS $-\mathrm{S}-\left(\mathrm{CH}_{2}\right)_{6}-\mathrm{OH}$ is shown for comparison.

For PVMS $-\mathrm{S}-\left(\mathrm{CH}_{2}\right)_{2}-\mathrm{OH}$, the lower temperature $(\beta)$ DRS peak is the smaller in amplitude, and appears at 180 to $210 \mathrm{~K}$ for applied frequencies ranging from $100 \mathrm{~Hz}$ to $5 \mathrm{kHz}$. At higher frequencies, the smaller $\beta$ peak shifts into the larger amplitude, higher temperature $\alpha$ peak, and is no longer clearly distinguishable. The $\beta$ peak positions form a straight line on an Arrhenius plot (see Experimental Methods), with 


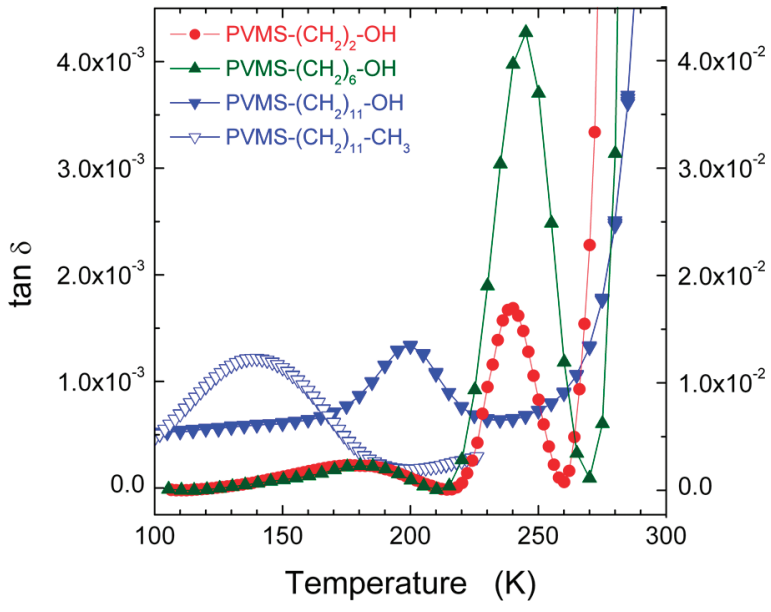

Figure 8. Dissipation factor for (right ordinate) PVMS $-\mathrm{S}-\left(\mathrm{CH}_{2}\right)_{2}-$ $\mathrm{OH}$ (filled red circles), $\mathrm{PVMS}-\mathrm{S}-\left(\mathrm{CH}_{2}\right)_{6}-\mathrm{OH}$ (filled green uptriangles), and (left ordinate) PVMS-S- $\left(\mathrm{CH}_{2}\right)_{11}-\mathrm{OH}$ (filled blue down-triangles), $\mathrm{PVMS}-\mathrm{S}-\left(\mathrm{CH}_{2}\right)_{11}-\mathrm{CH}_{3}$ (open blue down triangles) at $100 \mathrm{~Hz}$. A background due to ionic conductivity has been removed from each sweep. This sweep of PVMS $-\mathrm{S}-\left(\mathrm{CH}_{2}\right)_{11}-\mathrm{OH}$ data displays a melting peak at $\approx 315 \mathrm{~K}$. The higher temperature peak for PVMS-S$\left(\mathrm{CH}_{2}\right)_{2}-\mathrm{OH}$ and PVMS-S- $\left(\mathrm{CH}_{2}\right)_{6}-\mathrm{OH}$ is associated with $T_{\mathrm{g}}$.

slightly elevated attempt frequency of $\approx 10^{16} \mathrm{rad} / \mathrm{s}$. and a barrier of $10.9 \pm 0.8 \mathrm{kcal} / \mathrm{mol}$. For the $100 \mathrm{~Hz}$ to $20 \mathrm{kHz}$ frequency range, the higher amplitude and temperature $\alpha$ peak occurred at $240-250 \mathrm{~K}$ with only a small peak shift as a function of frequency. Such small peak shifts with frequency change are consistent with "glassy" or strongly interacting relaxations, which reflect the very rapid change in the rate of the molecular motion over very small changes in temperature. Thus, we assign this relaxation as associated with segmental motion and the glass transition.

The $\alpha$ DRS peak for the $-\left(\mathrm{CH}_{2}\right)_{6}-\mathrm{OH}$ samples appears at similar temperatures as the $-\left(\mathrm{CH}_{2}\right)_{2}-\mathrm{OH}$ equivalent, ranging from 245 to $270 \mathrm{~K}$, for $100 \mathrm{~Hz}$ to $20 \mathrm{kHz}$. As in PVMS-S$\left(\mathrm{CH}_{2}\right)_{2}-\mathrm{OH}$, the lower temperature peak in PVMS-S$\left(\mathrm{CH}_{2}\right)_{6}-\mathrm{OH}$ DRS data was smaller in amplitude than the $\alpha$-relaxation. At $100 \mathrm{~Hz}$, this $\beta$ peak occurred at the same location as the $-\left(\mathrm{CH}_{2}\right)_{2}-\mathrm{OH}(180 \mathrm{~K})$, before shifting into the higher temperature $\alpha$ feature at frequencies above $500 \mathrm{~Hz}$.

For PVMS $-\mathrm{S}-\left(\mathrm{CH}_{2}\right)_{11}-\mathrm{OH}$, two peaks corresponding to the $\beta$ and melting relaxations were observed in most specimens. The data in Figure $5 \mathrm{~d}$ are representative. The lower temperature $(\beta)$ peak had the larger amplitude and occurred at $200-230 \mathrm{~K}$, for $100 \mathrm{~Hz}$ to $20 \mathrm{kHz}$. For aged samples of $-\left(\mathrm{CH}_{2}\right)_{11}-\mathrm{OH}$, the melting peak was not present and an $\alpha$ relaxation associated with the $T_{\mathrm{g}}$ was observed.

PVMS-S- $\left(\mathrm{CH}_{2}\right)_{11}-\mathrm{CH}_{3}$ showed a high temperature peak in the dielectric relaxation data occurring at $\approx 290-$ $300 \mathrm{~K}$, which had characteristics associated with a melting transition (including a discontinuous change in capacitance at $T_{\mathrm{m}}$ ). It is not uncommon for side-chains with $n=11$ to crystallize, even without a terminal $-\mathrm{OH}$ group. A relaxation due to $T_{\mathrm{g}}$ was observed in the capacitance (enhanced by taking a derivative with respect to temperature). $T_{\mathrm{g}}, T_{\mathrm{m}}$, and $\beta$ peak locations from DRS for the $\mathrm{C}_{11}$ substituted networks appear in Table 1.

\section{Discussion}

A. Comparison of $T_{\mathrm{g}}$ as a Function of Structural Changes. DMTA and DRS data for PVMS networks were consistent in displaying a sharp dispersing peak varying in location from 145 to $155 \mathrm{~K}$ from $0.1 \mathrm{~Hz}$ to $20 \mathrm{kHz}$. Analysis of the data (see Experimental Methods) resulted in an estimated $T_{\mathrm{g}}=140 \pm 5 \mathrm{~K}$, which is consistent with the $T_{\mathrm{g}}$ value recorded by DSC. These values match the $T_{\mathrm{g}}$ of $143 \mathrm{~K}$ reported for linear PVMS. ${ }^{21}$ Thus, the cross-linking employed to form the network does not appear to alter $T_{\mathrm{g}}$ and the PVMS backbone retains its highly flexible properties. This observation also holds for PDMS (see Table 1; for comparison linear $T_{\mathrm{g}}$ for PDMS: $145-150 \mathrm{~K}$, depending on crystalline fraction ${ }^{22}$ ).

From the PVMS $-\mathrm{S}-\left(\mathrm{CH}_{2}\right)_{2}-\mathrm{OH}$ DRS data, $T_{\mathrm{g}}=230 \pm$ $10 \mathrm{~K}$, a nearly $100 \mathrm{~K}$ increase from the PVMS. This $T_{\mathrm{g}}$ is consistent with the DMTA value of $236 \pm 3 \mathrm{~K}$ at $1 \mathrm{~Hz}$. The DSC $T_{\mathrm{g}}$ of $215 \mathrm{~K}$ also displays a similar increase over the PVMS network value (148 K). This indicates that the $T_{\mathrm{g}}$ has been increased significantly due to the presence of the $-\mathrm{S}-$ $\left(\mathrm{CH}_{2}\right)_{2}-\mathrm{OH}$ side-chains. Dramatic changes in PVMS glass transition temperatures $(\approx 50-200 \mathrm{~K})$ have been observed previously when substituting bulky side-chains, which presumably hinder motion of the flexible siloxane backbone. ${ }^{21}$ The increase in $T_{\mathrm{g}}$ indicates that there are sufficient steric interactions between the pendent groups or between the pendent groups and backbone to alter the backbone dynamics.

The $\alpha$ DRS peak for the $-\left(\mathrm{CH}_{2}\right)_{6}-\mathrm{OH}$ samples appeared at similar temperatures as the $-\left(\mathrm{CH}_{2}\right)_{2}-\mathrm{OH}$ equivalent, with a $T_{\mathrm{g}}$ of $210 \pm 20 \mathrm{~K}$. The value from DSC was $208 \mathrm{~K}$. These $T_{\mathrm{g}}$ values overlap with the corresponding results for $-\left(\mathrm{CH}_{2}\right)_{2}-\mathrm{OH}$. The DMTA data are also similar for the two materials with a primary peak centered at $\approx 230-240 \mathrm{~K}$ (1 $\mathrm{Hz}$ ). While this lack of change in $T_{\mathrm{g}}$ when transitioning to the longer chain may be attributed to the well-known plasticizing effect of alkyl chains of moderate length, ${ }^{23}$ it could alternatively be caused by a slight variation of the $-\mathrm{S}-$ $\left(\mathrm{CH}_{2}\right)_{n}-\mathrm{OH}$ loading in the PVMS-S- $\left(\mathrm{CH}_{2}\right)_{n}-\mathrm{OH}$ network. Though, as we note in the Experimental Methods, the loading of $-\mathrm{S}-\left(\mathrm{CH}_{2}\right)_{n}-\mathrm{OH}$ inside the PVMS-S$\left(\mathrm{CH}_{2}\right)_{n}-\mathrm{OH}$ network appeared to be approximately the same, as revealed by IR spectroscopy.

PVMS-S- $\left(\mathrm{CH}_{2}\right)_{11}-\mathrm{OH}$ displayed $T_{\mathrm{m}}$ features in the range 299-311 K (DSC) and 294-312 K (DMTA). Evidence of melting (often associated with a large discontinuous change in the $\varepsilon^{\prime \prime}$ or, equivalently, capacitance) was observed in the dielectric data at $300-320 \mathrm{~K}$. For most DRS samples, this was the dominant high temperature relaxation and no peak associated with the glass transition was observed. For some samples, particularly those that had been aged at ambient conditions for a year or so after fabrication, a peak ranging from 282 to $287 \mathrm{~K}(320 \mathrm{~Hz}$ to $20 \mathrm{kHz})$ was observed. This results in an estimated $T_{\mathrm{g}}$ in the $270-290 \mathrm{~K}$ range, which is consistent with that observed in the DSC $(284.5 \mathrm{~K})$. Features in DMTA associated with the $\alpha$ relaxation varied in position from 240 to $270 \mathrm{~K}$. These $T_{\mathrm{g}}$ values are significantly higher than for the networks with shorter pendant groups, indicating that the backbone dynamics are further constrained by the longer chains. Generally the DMTA and DS data from $-\left(\mathrm{CH}_{2}\right)_{11}-\mathrm{OH}$ samples exhibited more complex structure and sample to sample differences than the other materials, which is consistent with a semicrystalline material.

In order to study the role of the terminal group in modifying dynamics within the network, PVMS-S$\left(\mathrm{CH}_{2}\right)_{2}-\mathrm{CH}_{3}$ and PVMS-S$-\left(\mathrm{CH}_{2}\right)_{11}-\mathrm{CH}_{3}$ were also investigated. In a DMTA study of PVMS-S $-\left(\mathrm{CH}_{2}\right)_{2}-\mathrm{CH}_{3}$ and PVMS $-\mathrm{S}-\left(\mathrm{CH}_{2}\right)_{2}-\mathrm{OH}$, the $T_{\mathrm{g}}$ dropped significantly from $236 \pm 3 \mathrm{~K}$ to $190 \pm 3 \mathrm{~K}$ without the $-\mathrm{OH}$ group present (Table 1). This value is still larger than the $T_{\mathrm{g}}$ for the PVMS network without pendent groups $(\approx 150 \mathrm{~K})$. The $-\left(\mathrm{CH}_{2}\right)_{11}-$ 
analogues were studied by DRS. When comparing the $-\left(\mathrm{CH}_{2}\right)_{11}-\mathrm{CH}_{3}$ pendent group with the more polar $-\left(\mathrm{CH}_{2}\right)_{11}-$ $\mathrm{OH}$, the $T_{\mathrm{g}}$ only decreased slightly to $265 \pm 5 \mathrm{~K}$ (compared with $-\left(\mathrm{CH}_{2}\right)_{11}-\mathrm{OH}$ estimate of $\left.270-290 \mathrm{~K}\right)$. Interestingly, the DSC measurement of $T_{\mathrm{g}}$ shows a much larger decrease from 285 to $210 \mathrm{~K}$. These results indicate that both the length and termination of the pendent group affect the glass transition temperature; that is, that pendent-pendent or pendentbackbone interactions determine the effective $T_{\mathrm{g}}$.

B. Sub- $\boldsymbol{T}_{\mathbf{g}}$ Relaxations. The low-temperature $(\beta)$ peak in the PVMS-S- $\left(\mathrm{CH}_{2}\right)_{2}-\mathrm{OH}$ DRS data is consistent with rotation within the pendent-group alkyl chains. Relaxations due to local motions within side-chains often follow Arrhenius dynamics. Side-chain peaks are generally smaller in amplitude than those associated with $T_{\mathrm{g}}$ ( $\alpha$ relaxations) and appear at sub- $T_{\mathrm{g}}$ temperatures. There exists a wellknown local relaxation in the $120-150 \mathrm{~K}$ range (for $100 \mathrm{~Hz}$ ) that is associated with alkyl side groups ${ }^{24-27}$ and has also been observed in alkyl self-assembled monolayers. 9,28 Previous workers have assigned this relaxation to a crankshaftlike motion where two gauche defects alternate in orientation without significantly changing the average volume taken up by the chain. ${ }^{29}$ The presence of the polar $-\mathrm{OH}$ group and/or polarized bonds near $-\mathrm{S}-$ would enable dielectric observation of these motions. Although the exact nature of the relaxation is still debated, ${ }^{26,27}$ it is mostly independent of the backbone structure ${ }^{25}$ and thus a common feature for polymers with alkyl side-chains. A similar local relaxation occurs in polyethylene (named the PE- $\gamma$ relaxation in that case). ${ }^{28,29}$ The barriers observed for this $\mathrm{PE}-\gamma$ relaxation are generally $\approx 6-7 \mathrm{kcal} / \mathrm{mol}$. However, in side-chain polymers this relaxation has been observed at higher temperature (larger barriers) when interchain interactions are present. ${ }^{30}$ Our results are consistent with the presence of a PE- $\gamma$-like relaxation, with an elevation in barrier (to $10.9 \pm 0.8 \mathrm{kcal} /$ mol) resulting from interchain interactions due to the $-\mathrm{OH}$ group. Sub- $T_{\mathrm{g}}$ or side-chain motions are not generally observable in DSC, which is consistent with this assignment.

Comparing peak positions for the $\beta$ relaxation from DMTA and DRS $(190 \mathrm{~K}$ at $1 \mathrm{~Hz}$, and $180 \mathrm{~K}$ at $100 \mathrm{~Hz})$ it appears that the barrier is lower in the dielectric case. This has previously been observed for other local relaxations. ${ }^{26,31}$ In that case, the authors argued that the coupling between the electric field and the dipole was direct; whereas the coupling between the applied mechanical stress and the side-chains was more indirect, and therefore associated with a higher barrier. Thus, the two techniques measured different responses. In our materials only the terminal $-\mathrm{OH}$ group or a polarized bond near the thiolene attachment need respond to provide a dielectric signal, which may have slightly different dynamics than a relaxation in the interior of the chain.

Comparing the response of $-\left(\mathrm{CH}_{2}\right)_{2}-\mathrm{OH}$ and $-\left(\mathrm{CH}_{2}\right)_{6}-$ $\mathrm{OH}$ pendent groups, we find that the DMTA data is similar for both, with peaks at $\approx 190 \mathrm{~K}$. This similarity also holds for the DRS data $(180 \mathrm{~K}$ for $100 \mathrm{~Hz})$. Considering the constraints on the data due to peak merging, we conclude that the relaxation is similar for $-\mathrm{S}-\left(\mathrm{CH}_{2}\right)_{2}-\mathrm{OH}$ and $-\mathrm{S}-\left(\mathrm{CH}_{2}\right)_{6}-$ $\mathrm{OH}$ pendent groups.

In contrast, the $\beta$ dielectric relaxation in PVMS-S$\left(\mathrm{CH}_{2}\right)_{11}-\mathrm{OH}$ (DRS) was shifted to higher temperatures $(200 \mathrm{~K}$ at $100 \mathrm{~Hz})$. DMTA data showed an equivalent $\beta$ relaxation in the range of $180-197 \mathrm{~K}$ at $1 \mathrm{~Hz}$. These peak positions are higher in temperature than for the shorter sidechains, indicating slower dynamics. Analysis of the DRS data revealed that the $-\left(\mathrm{CH}_{2}\right)_{11}-\mathrm{OH}$ pendent groups have significant interaction, with an elevated apparent attempt frequency of $\approx 10^{20} \mathrm{rad} / \mathrm{s}$ and an effective barrier of $16 \pm$ $0.8 \mathrm{kcal} / \mathrm{mol}$. A Starkweather analysis (see Experimental Methods) showed $\Delta S=115 \pm 32 \mathrm{~J} / \mathrm{mol} / \mathrm{K}$, compared to $\Delta S=60 \pm 10 \mathrm{~J} / \mathrm{mol} / \mathrm{K}$ for $-\left(\mathrm{CH}_{2}\right)_{2}-\mathrm{OH}$. Thus, we conclude that the $-\left(\mathrm{CH}_{2}\right)_{11}-\mathrm{OH}$ chains are significantly more interacting than the $-\left(\mathrm{CH}_{2}\right)_{2}-\mathrm{OH}$ or $-\left(\mathrm{CH}_{2}\right)_{6}-\mathrm{OH}$ side-chains. This is consistent with previous observations of crystallization of the $-\left(\mathrm{CH}_{2}\right)_{11}-\mathrm{OH}$ side-chains. Although this relaxation has interacting dynamics, it did not appear in the DSC sweep, which is representative of an interacting side-chain relaxation rather than a glass or melting transition.

The amplitude of the DRS $\beta$ relaxation PVMS $-\mathrm{S}-$ $\left(\mathrm{CH}_{2}\right)_{11}-\mathrm{OH}$ increased with increasing temperature (higher measurement frequency) in contrast to the short side-chain network data where the amplitude was constant. Such an increase indicates that the number of units participating in the relaxation is increasing with temperature. ${ }^{32,33}$ This could occur because the side-chain relaxation is localized in the amorphous regions, and the amorphous fraction is increasing with temperature. In addition, an asymmetrical potential surface could explain this result. In thermally activated hopping, any reorienting group is hindered by a potential surface with more than one accessible minimum, i.e., reorientation involves transition from one minimum to another over an effective barrier $\Delta U$. However, if the energy difference between the minima, $B^{\prime}$, is sufficiently large (compared to $k T$ ), a particular unit will remain frozen in a single well, and thus not reorient. For a distribution of $B^{\prime}$ values, as the temperature increases, more units will be available for reorientation. Thus, in general, an increasing signal with temperature is associated with asymmetrical potential surfaces. Such asymmetry can occur when strong local interactions are present, which is consistent with the significant interactions between the $-\left(\mathrm{CH}_{2}\right)_{11}-\mathrm{OH}$ pendent groups.

The $\beta$ transition was also studied for methyl-terminated pendent groups. The relaxation in PVMS-S- $\left(\mathrm{CH}_{2}\right)_{2}-\mathrm{CH}_{3}$ shifts downward from that in PVMS-S- $\left(\mathrm{CH}_{2}\right)_{2}-\mathrm{OH}$, indicating faster dynamics (DMTA measurements, Table 1). This occurs in the $-\left(\mathrm{CH}_{2}\right)_{11}-$ system as well, as studied by DRS. In that case, the peak shifted downward significantly $(140-170 \mathrm{~K}$, from $100 \mathrm{~Hz}$ to $20 \mathrm{kHz}$ ), and displayed a resultant barrier to rotation of $7.7 \pm 0.5 \mathrm{kcal} / \mathrm{mol}$ (compared to $16 \mathrm{kcal} / \mathrm{mol}$ for the $\mathrm{C}_{11}-\mathrm{OH}$ networks). Starkweather analysis revealed $\Delta S=34 \pm 12 \mathrm{~J} / \mathrm{mol} / \mathrm{K}$, indicating a significant drop in interaction compared with the $-\left(\mathrm{CH}_{2}\right)_{11}-$ $\mathrm{OH}$ case, and similar or lower interactions as within the sidechains of PVMS-S- $\left(\mathrm{CH}_{2}\right)_{2}-\mathrm{OH}$. Thus, the presence of the $-\mathrm{OH}$ group increases the effective barrier (in both the $\mathrm{C}_{2}$ and $\mathrm{C}_{11}$ cases), and in the absence of the $-\mathrm{OH}$ group, the barrier to rotation and peak location of the $\beta$-motion are similar to $\gamma$-PE relaxation in alkyl side-chain polymers. This confirms our assignment of the relaxation.

C. Relationship between $T_{\mathrm{g}}$ and the Macroscopic Responsiveness. Generally, the three techniques (DSC, DRS, and DMTA) agree in their determination of $T_{\mathrm{g}}$ within the experimental error. Cross-linking to form the network does not affect the flexibility of the PVMS backbone; however upon grafting of the $-\mathrm{S}-\left(\mathrm{CH}_{2}\right)_{2}-\mathrm{OH}$ pendent group $T_{\mathrm{g}}$ increases by $>60 \mathrm{~K}$. The $T_{\mathrm{g}}$ of PVMS $-\mathrm{S}-\left(\mathrm{CH}_{2}\right)_{11}-\mathrm{OH}$ is significantly higher than that of the other substituted systems, indicating that the strong interactions among the $-\mathrm{S}-\left(\mathrm{CH}_{2}\right)_{11}-\mathrm{OH}$ groups hinder substantially the motion of the siloxane backbone.

The trends in $T_{\mathrm{g}}$ match qualitatively with the response rate detected in the DCA experiments at room temperature. Namely, the response rate at room temperature of PVMS $-\mathrm{S}-\left(\mathrm{CH}_{2}\right)_{n}-\mathrm{OH}$ increases with decreasing $T_{\mathrm{g}}$. This 
trend is not unexpected as materials farther above their glass transition temperature should possess faster dynamics. To that end, PVMS exhibits the fastest response rate, followed by $\mathrm{PVMS}-\mathrm{S}-\left(\mathrm{CH}_{2}\right)_{2}-\mathrm{OH}$ and $\mathrm{PVMS}-\mathrm{S}-\left(\mathrm{CH}_{2}\right)_{6}-\mathrm{OH}$ and finally, PVMS $-\mathrm{S}-\left(\mathrm{CH}_{2}\right)_{11}-\mathrm{OH}$ exhibits the most sluggish response.

Recall that earlier in the paper we pointed out that the DCA experimental data could not be fitted satisfactorily with a simple exponential decay function. In contrast, a second order exponential decay, i.e., eq 2, provided a better fit. Interestingly, the decay coefficients $\beta_{1}$ and $\beta_{2}$ used in eq 2 plotted in Figure 3 exhibit two distinct trends. While $\beta_{1}$ decreases steadily with increasing the length of the methylene spacer, $\beta_{2}$ is independent of the size of the pendent group. If the network $T_{\mathrm{g}}$ is well correlated with the response time, as reflected in $\beta_{1}$, this would indicate that the segmental dynamics control the motion of the pendent group through the network. The time scale of segmental fluctuations is given by $\tau$ micro, the average time between reorientation events, the value of which (at room temperature) can be estimated from the DRS data. This $\tau$ micro should be related to the macroscopic response time $\tau$ macro $=1 / \beta_{1}$ from the analysis of the dynamic contact angle ( $c f$. Figures 2 and 3 ). Thus, in order to further correlate microscopic and macroscopic motion, we fit our DRS relaxation data (see Experimental Methods), and then extrapolated this fit to estimate $\tau$ micro at room temperature where the DCA measurements were taken. This is similar to the extrapolation utilized to determine $T_{\mathrm{g}}$. As already discussed, these $T_{\mathrm{g}}$ values (listed in Table 1) agree well with data from DSC and DMTA data taken at $1 \mathrm{~Hz}$, which indicates that the fits are appropriate.

Since many segmental fluctuations would be required for a single $-\mathrm{S}-\left(\mathrm{CH}_{2}\right)_{n}-\mathrm{OH}$ group to emerge from the surface upon application of water, we expect the microscopic and macroscopic relaxation times to vary by many orders of magnitude. The $\tau$ micro values for $-\mathrm{S}-\left(\mathrm{CH}_{2}\right)_{2}-\mathrm{OH}$ and $-\mathrm{S}-\left(\mathrm{CH}_{2}\right)_{6}-\mathrm{OH}$ were similar whereas the value for $-\mathrm{S}-\left(\mathrm{CH}_{2}\right)_{11}-\mathrm{OH}$ was about ten times larger. These ratios are similar to those for the equivalent $1 / \beta_{1}$ values. Comparing the four $\tau$ pairs (for the different network types) we find $\tau$ macro $\approx 1 \times 10^{9} \tau$ micro. We conclude that there is a good qualitative correlation between these two $\tau$ estimates, which result from completely isolated and independent measurements of the samples properties.

We could find no correlations between the slower macroscopic relaxation time (given by the inverse of $\beta_{2}$ ) and any other physical quantity measured. The slower process is unlikely to originate from the relaxations of the side groups because those relaxations are likely faster than or have similar dynamics to the segmental motions at room temperature. Moreover, the process responsible for $\beta_{2}$ should be independent of the molecular architecture of the silicone elastomer chain. Unlike other analytical methods employed in this work, which probe the bulk properties of the system, DCA is sensitive only to the surface and near subsurface region of the network. We thus tentatively associate the slower relaxation process observed in the DCA data with the rearrangement of subsurface chains that move when the macromolecules present at the surface reorganize. This process may thus be associated tentatively with the overall mobility of the networks that would depend on the average molecular weight between the cross-link points; those were exactly the same in all specimens studied. In order to test this hypothesis, experiments similar to the one described here would have to be carried out using networks that possess different cross-link densities.
D. Relationship between Pendant Group Interactions and $\boldsymbol{T}_{\mathbf{g}}$. Generally, longer pendent groups and stronger interactions between the pendent groups (as exemplified by the $-\left(\mathrm{CH}_{2}\right)_{11}-\mathrm{OH}$ case) leads to an increase in $T_{\mathrm{g}}$, as the steric and/or dipolar interactions between the chains limit the flexibility of the PVMS backbone. These interchain interactions also affect, and are reflected in, the $\beta$ relaxation. Thus, although the $\beta$ relaxation within the pendent groups is not directly related to the responsiveness of the networks, observing its dynamics enhances our understanding of the pendent group interactions that lead to a resultant network $T_{\mathrm{g}}$, and thus a characteristic response time to applied stimulus.

The $\alpha$ relaxation results indicate that both steric and dipolar interactions can effect interchain or chain-backbone interactions and thus the stiffening of the PVMS network. For the short chain case, both effects appear distinctly important, as exhibited in the difference in $T_{\mathrm{g}}$ values for the $-\left(\mathrm{CH}_{2}\right)_{2}-\mathrm{OH}$ and $-\left(\mathrm{CH}_{2}\right)_{2}-\mathrm{CH}_{3}$ networks. For the longer chain, the situation is less clear, in part due to the complications of measuring a semicrystalline material under a variety of conditions. It may be that steric interactions between the side-chains are the dominant effect for long chains, and thus primarily responsible for the increase in $T_{\mathrm{g}}$, explaining why the two $-\left(\mathrm{CH}_{2}\right)_{11}-$ pendent groups result in a similar $T_{\mathrm{g}}$.

The polarity of the pendent group is important because it determines the magnitude of the response. As outlined above, the flexibility of the network, through which the pendent group must travel, affects the response time. For this particular set of networks, these two effects are correlated. Because the PVMS backbone is highly flexible, interactions between the pendent groups stiffen the network, raising $T_{\mathrm{g}}$, and slowing the response time. Increasing the difference in hydophobicity between the two switching groups (the $-\mathrm{CH}_{3}$ and the vinyl or $-\mathrm{OH}$ pendent terminus), creates a larger drive (energy difference) to respond to a change in environment (application of water or air). However, rather than enhancing the response time (due to the increased driving force) the increased polarity of the pendent groups causes interactions which stiffens the network, thus (counterintuitively) slowing down the response.

These results reveal the delicate balance needed in the design of such responsive networks. For instance, decreasing the density of pendent groups would significantly decrease interchain interactions and thus allow for groups with stronger polarity without significant increases in $T_{\mathrm{g}}$. However, a lower density of pendent groups would also decrease the magnitude of the response. An ideal design will utilize an optimal density and polarity of pendent groups to maximize both response size and speed.

\section{Conclusions}

By combining dielectric, calorimetric, and mechanical measurements we observed both intrapendent and PVMS-backbone relaxations within stimulus-responsive PVMS networks. $T_{\mathrm{g}}$ was not affected by network formation but increased by $\approx 40 \mathrm{~K}$ with introduction of the $-\mathrm{S}-\left(\mathrm{CH}_{2}\right)_{2}-\mathrm{CH}_{3}$ pendent, and another $25-40 \mathrm{~K}$ for the polar analogue, i.e., $-\mathrm{S}-\left(\mathrm{CH}_{2}\right)_{2}-\mathrm{OH}$. $T_{\mathrm{g}}$ values for PVMS-S- $\left(\mathrm{CH}_{2}\right)_{2}-\mathrm{OH}$ and PVMS-S- $\left(\mathrm{CH}_{2}\right)_{6}-\mathrm{OH}$ were similar, but the $T_{\mathrm{g}}$ increased significantly $(\approx 50 \mathrm{~K})$ for the longer pendent group, i.e., $-\left(\mathrm{CH}_{2}\right)_{11}-\mathrm{OH}$ and $-\left(\mathrm{CH}_{2}\right)_{11}-\mathrm{CH}_{3}$. Thus, as the pendent groups are altered, the network $T_{\mathrm{g}}$ changes, as the different groups constrained the siloxane backbone to differing degrees. This indicates that network dynamics can be tuned significantly $\left(\Delta T_{\mathrm{g}}=130 \mathrm{~K}\right)$ by adjusting the size, shape, and polarity of the pendent groups. 
$\beta$ relaxations were also observed for all pendent groups, and were assigned to rotation within the pendent alkyl chain. Study of the $\beta$ relaxation enabled an understanding of the changes in $T_{\mathrm{g}}$ as resulting from steric or dipolar interchain or chain-backbone interactions which stiffen the system.

For macroscopic responsiveness the pendent groups must travel through the PVMS network, thus the flexibility of the network appears to be one limitation to response time. For systems with significant interactions between the pendent groups, $T_{\mathrm{g}}$ is elevated and the response time is slow. These two effects may arise from the same source; namely, the increased interactions between pendent groups, which increase the rigidity of the entire system. When pendent groups are less interacting, some of the flexibility of the PVMS backbone is retained, and macroscopic response times approach that of the unsubstituted PVMS. Taken as a whole, these results indicate that a holistic approach, understanding both the driving forces and the intrinsic molecular motions within a system, is desirable for effective design of stimuli-responsive systems.

Acknowledgment. J.A.C.-W. and J.G. acknowledge the support through the Office of Naval Research, Grant No. N0001408-1-0369. We thank Professor Saad Khan and Professor Russell Gorga for the generous use of their DSC and DMTA equipment.

\section{References and Notes}

(1) Minko, S. Polym. Rev. 2006, 46, 397-420.

(2) Cohen Stuart, M. A.; Huck, W. T. S.; Genzer, J.; Muller, M.; Ober, C.; Stamm, M.; Sukhorukov, G. B.; Szleifer, I.; Tsuktruk, V. V.; Urban, M.; Winnik, F.; Zauscher, S.; Luzinov, I.; Minko, S. Nature Mater. 2010, 9, 101-103.

(3) Luzinov, I.; Minko, S.; Tsukruk, V. V. Prog. Polym. Sci. 2004, 29 , 635-698.

(4) Luzinov, I.; Minko, S.; Tsukruk, V. V. Soft Matter 2008, 4, $714-725$.

(5) Crowe, J. A.; Genzer, J. J. Am. Chem. Soc. 2005, 127, 17610-17611.

(6) Crowe-Willoughby, J. A.; Genzer, J. Adv. Funct. Mater. 2009, 19, 460-469

(7) Efimenko, K.; Crowe, J. A.; Manias, E.; Schwark, D. W.; Fischer, D. A.; Genzer, J. Polymer 2005, 46, 9329-9341.
(8) Herczynska, L.; Lestel, L.; Boileau, S.; Chojnowski, J.; Polowinski, S. Eur. Polym. J. 1999, 35, 1115-1122.

(9) Scott, M. C.; Stevens, D. R.; Bochinski, J. R.; Clarke, L. I. ACS Nano 2008, 2, 2392-2400.

(10) Rotella, C.; Napolitano, S.; Wuebbenhorst, M. Macromolecules 2009, 42, 1415-1417.

(11) McCrum, N. G.; Read, B. E.; Williams, G. Anelastic and Dielectric Effects in Polymeric Solids, Dover 1991 ed.; Wiley: London, 1967.

(12) Horansky, R. D.; Clarke, L. I.; Winston, E. B.; Price, J. C. Phys. Rev. B 2006, 74 (5), 054306.

(13) Sidebottom, D. L.; Green, P. F.; Brow, R. K. J. Non-Cryst. Solids 1997, 222, 354-360.

(14) Fulcher, G. S. J. Am. Ceram. Soc. 1925, 8, 339-355.

(15) Tammann, G.; Hesse, W. Z. Anorg. Allgem. Chem. 1926, 156, 14.

(16) Vogel, H. Phys. Z. 1921, 22, 645-646.

(17) Angell, C. A. Science 1995, 267 (5206), 1924-1935.

(18) Starkweather, H. W. Macromolecules 1981, 14, 1277-1281.

(19) Murayama, T. Dynamic Mechanical Analysis of Polymeric Materials; Elsevier Scientific Publishing Company: Amsterdam, 1978.

(20) Ferry, J. D. Viscoelastic Properties of Polymers; John Wiley \& Sons: New York, 1961.

(21) Gupta, S. K.; Weber, W. P. Macromolecules 2002, 35, 33693373

(22) Lund, R.; Alegria, A.; Goitandia, L.; Colmenero, J.; Gonzalez, M. A.; Lindner, P. Macromolecules 2008, 41, 1364-1376.

(23) Painter, P. C.; Coleman, M. M. Essentials of Polymer Science and Engineering; DEStech Publications: Lancaster, PA, 2009.

(24) Diazcalleja, R. J. Polym. Sci., Part B: Polym. Phys. 1979, 17, 1395 1401.

(25) Genix, A. C.; Laupretre, F. Macromolecules 2005, 38, 2786-2794.

(26) Sanchis, M. J.; Diaz-Calleja, R.; Pelissou, O.; Gargallo, L.; Radic, D. Polymer 2004, 45, 1845-1855.

(27) Tadano, K.; Tanaka, Y.; Shimizu, T.; Yano, S. Macromolecules 1999, 32, 1651-1660.

(28) Zhang, Q.; Archer, L. A. J. Phys. Chem. B 2006, 110, 4924-4928.

(29) Boyd, R. H.; Breitlin., Sm. Macromolecules 1974, 7, 855-862.

(30) Koizumi, S.; Tadano, K.; Tanaka, Y.; Shimidzu, T.; Kutsumizu, S.; Yano, S. Macromolecules 1992, 25, 6563-6567.

(31) Mohomed, K.; Gerasimov, T. G.; Moussy, F.; Harmon, J. P. Polymer 2005, 46, 3847-3855.

(32) Daniel, V. V., Dielectric Relaxation; Academic Press: London and New York, 1967.

(33) Horansky, R. D.; Clarke, L. I.; Price, J. C.; Khuong, T. A. V.; Jarowski, P. D.; Garcia-Garibay, M. A. Phys. Rev. B 2005, 72, 014302 . 